\title{
In situ coupling of N-doped lignin-derived carbon-encapsulated CoFe-CoxN heterojunction for oxygen evolution reaction
}

\author{
Xuliang Lin ${ }^{1}$, Jianglin $\mathrm{Liu}^{1}$, Linjun $\mathrm{Wu}^{1}$, Liheng $\mathrm{Chen}^{1}$, Yi Qi ${ }^{1}$, Zhongjie Qiu ${ }^{1}$, Huafeng \\ Dong $^{1}$, Yanlin Qin ${ }^{1}$, and Xueqing Qiu ${ }^{1}$ \\ ${ }^{1}$ Guangdong University of Technology
}

February 20, 2022

\begin{abstract}
Exploring highly active and stable electrocatalyst for oxygen evolution reaction is important for the development of water splitting and rechargeable metal-air batteries. Herein, a hybrid electrocatalyst of CoFe alloy and CoxN heterojunction encapsulated and embedded in N-doped carbon support (CoFe-CoxN@NC) was in situ coupling via a pyrolysis process of a novel coordination polymer from lignin biomacromolecule. CoFe-CoxN@NC exhibited an excellent OER activity with a low overpotential of $270 \mathrm{mV}$ at $10 \mathrm{~mA}^{*} \mathrm{~cm}-2$ and stability with increment of $20 \mathrm{mV}$, comparable to commercial Ir/C. DFT calculations revealed that CoxN and $\mathrm{N}$-doped grapheme encapsulation can reduce the binding strength between ${ }^{*} \mathrm{O}$ and CoFe alloy, prevent metals leaching and agglomeration, and improve electron transfer efficiency, thereby, remarkably enhancing the OER activity and stability. In situ coupling strategy of alloy and nitride heterojunction on N-doped lignin-derived carbon provided a promising and universal catalyst design for the development of renewable energy conversion technologies.
\end{abstract}

In situ coupling of N-doped lignin-derived carbon-encapsulated $\mathrm{CoFe}_{-} \mathrm{Co}_{x} \mathrm{~N}$ heterojunction for oxygen evolution reaction

Xuliang Lin ${ }^{1}$, Jianglin $\mathrm{Liu}^{1}$, Linjun $\mathrm{Wu}^{1}$, Liheng $\mathrm{Chen}^{1}$, Yi Qi ${ }^{1}$, Zhongjie Qiu ${ }^{1}$, Huafeng Dong ${ }^{2}$, Yanlin Qin $^{1, *}$, Xueqing Qiu ${ }^{1, *}$

${ }^{1}$ Guangdong Provincial Key Laboratory of Plant Resources Biorefinery, School of Chemical Engineering and Light Industry, Guangdong University of Technology, Guangzhou, 510006, China

${ }^{2}$ School of Physics and Optoelectronic Engineering, Guangdong University of Technology, Guangzhou, 510006, China

* Corresponding Author

E-mail: ylqin@gdut.edu.cn (Y.L. Qin);cexqqiu@scut.edu.cn(X.Q. Qiu)

\section{Abstract}

Exploring highly active and stable electrocatalyst for oxygen evolution reaction is important for the development of water splitting and rechargeable metal-air batteries. Herein, a hybrid electrocatalyst of $\mathrm{CoFe}$ alloy and $\mathrm{Co}_{\mathrm{x}} \mathrm{N}$ heterojunction encapsulated and embedded in $\mathrm{N}$-doped carbon support (CoFe-Co $\left.\mathrm{N} N \mathrm{NC}\right)$ was in situ coupling via a pyrolysis process of a novel coordination polymer from lignin biomacromolecule. $\mathrm{CoFe}-\mathrm{Co}_{\mathrm{x}} \mathrm{N} @ \mathrm{NC}$ exhibited an excellent OER activity with a low overpotential of $270 \mathrm{mV}$ at $10 \mathrm{~mA} \cdot \mathrm{cm}^{-2}$ and stability with increment of $20 \mathrm{mV}$, comparable to commercial $\mathrm{Ir} / \mathrm{C}$. DFT calculations revealed that $\mathrm{Co}_{\mathrm{x}} \mathrm{N}$ and $\mathrm{N}$-doped grapheme encapsulation can reduce the binding strength between ${ }^{*} \mathrm{O}$ and $\mathrm{CoFe}$ alloy, prevent 
metals leaching and agglomeration, and improve electron transfer efficiency, thereby, remarkably enhancing the OER activity and stability. In situ coupling strategy of alloy and nitride heterojunction on N-doped lignin-derived carbon provided a promising and universal catalyst design for the development of renewable energy conversion technologies.

Keywords : Lignin-derived carbon; CoFe alloy; Heterojunction; Oxygen evolution reaction; Electrocatalysis.

\section{Introduction}

Electrochemical water splitting powered by solar, wind and tidal renewable energies is an ideal green and costeffective hydrogen production path, and there are no carbon-containing compounds discharged ${ }^{1,2}$. Water splitting consists of two half reactions: hydrogen evolution reaction (HER) on the cathode and oxygen evolution reaction (OER) on the anode. The OER process suffers from multiple steps of proton-coupled electron transfer, thereby causing very sluggish reaction kinetics and high overpotential ${ }^{3,4}$. Up to now, noble metals and metal oxides, such as Ir and $\mathrm{Ru}$, are the state-of-the-art catalysts for the OER process, however, their scarcity, high costs and poor stability has severely hindered their widespread commercialization 5-7. Therefore, it is highly desirable to search and develop highly efficient, stable, and cost-effective OER electrocatalysts ${ }^{3,8}$.

Owing to the intrinsic electron structure, special orbitals and high carrier mobility, transition metals Co-based and Ni-based catalysts have been widely investigated toward OER and perform great promise for potential applications ${ }^{9-11}$. A wide variety of Co-based catalysts have been well investigated for OER, including metal oxides ${ }^{12,13}$, layered double hydroxides ${ }^{14,15}$, bimetallic alloys ${ }^{16-20}$, metallic nitrides ${ }^{21,22}$ and phosphides ${ }^{23}$. Co-based oxides and layered double hydroxides are limited toward electrocatalytic performance for their poor electrical conductivity, which hinder the electron transfer ${ }^{11,24}$. Doping Fe element in Co species adjusts the local electronic structure and enhances the active sites, which can boost the OER electrocatalytic activity 18,25-29. In addition, bimetallic alloys and $\mathrm{Co}_{\mathbf{x}} \mathrm{N}$ nitrides exhibit high OER catalytic activities, attributed to their superior electrical conductivity ${ }^{22,30,31}$. However, Co-based monometallic or bimetallic catalysts are usually unstable and oxidized during the OER process in alkaline solution ${ }^{32}$. What's more, bimetallic alloys show the strong binding with oxygen intermediates toward OER, that require the high overpotential to overcome the reaction barriers ${ }^{25}$.

Carbon-based nanomaterials have shown great potential in the design of metal based electrocatalysts for their cost-efficient, high specific surface area, excellent conductivity, and favorable durability in a harsh environment ${ }^{27,28,33-37}$. However, the inert surface of carbon materials usually leads to the weak interaction between the metal nanoparticles and supports, which make it difficult to effectively regulate the electronic structure of metal nanoparticles and improve their catalytic activity ${ }^{27,28}$. Biorefinery lignin is the most promising carbon precursor instead of petroleum and coal resources, owing to its second largest natural organic polymer after cellulose ${ }^{38,39}$. In addition, with a three-dimensional network structure formed by phenylpropane units, lignin is rich in phenolic hydroxyl groups, alcoholic hydroxyl groups and part of carboxyl groups, and its carbon content is as high as $60 \%{ }^{40,41}$. Moreover, lignin-derived carbon have been reported as the catalyst support in the applications of electrocatalysis ${ }^{42,43}$, photocatalysis degradation ${ }^{44,45}$, FischerTropsch synthesis ${ }^{46,47}$ and other fields ${ }^{48,49}$ in the last few years, but most of the lignin-derived carbon catalyst are prepared using direct carbonization of lignin followed by impregnation of metal active ingredients, of which was easily dissoluble and difficult to effectively inhibit their agglomeration, causing the inferior activity and durability ${ }^{50}$.

In this work, making full use of the inherent properties and abundant carboxyl/hydroxyl functional groups of lignin biomacromolecule to precisely coordinate with transition metal ions with $\mathrm{Co}^{2+}$ and $\mathrm{Fe}^{3+}$ by aqueous self-assembly process, and form the lignin-based CoFe bimetallic supramolecules, then co-doped with nitrogen precursor urea in situ pyrolyzing at high temperature to obtain the desired CoFe biometallic active nano 
particles. The effects of the pyrolysis temperature, urea dosage, Fe/Co metal ratio and metal/lignin ratio during synthesis process on the structure and OER electrocatalytic activity were investigated. To our delight, $\mathrm{Co}_{\mathrm{x}} \mathrm{N}$ component was in situ generated other than CoFe alloy during the pyrolysis and doping of urea revealed by the systematic characterization, and coupled with $\mathrm{CoFe}$ alloy to form the $\mathrm{CoFe}-\mathrm{Co}_{\mathrm{x}} \mathrm{N}$ heterojunction encapsulated by the graphic carbon layers and located on the nitrogen-doped lignin-derived shell-core carbon support ( $\left.\mathrm{CoFe}-\mathrm{Co}_{\mathrm{x}} \mathrm{N} @ \mathrm{NC}\right)$, that optimize the adsorption/desorption strength between the OER intermediates and metallic active site, disperse and decrease the size of $\mathrm{CoFe}-\mathrm{Co}_{\mathrm{x}} \mathrm{N}$ heterojunction, and prevent their aggregation, endowing the as-synthesized catalyst $\mathrm{CoFe}-\mathrm{Co}_{\mathrm{x}} \mathrm{N} @ \mathrm{NC}$ exhibited excellent OER electrocatalytic activity and stability in an alkaline medium.

\section{Experimental section}

\subsection{Materials}

Enzymatic hydrolysis lignin (EHL) isolated from the corncob bio-refinery residue through alkali dissolving, acid precipitation, water washing, drying, ball milling and sieving, was provided by Shandong Longli Biotechnology Co., Ltd. Iron chloride hexahydrate $\left(\mathrm{FeCl}_{3} * 6 \mathrm{H}_{2} \mathrm{O}, \mathrm{AR} 99 \%\right)$, cobalt nitrate hexahydrate $\left(\mathrm{Co}\left(\mathrm{NO}_{3}\right)_{2} * 6 \mathrm{H}_{2} \mathrm{O}\right.$, AR 99\%), urea $\left(\mathrm{CO}\left(\mathrm{NH}_{2}\right)_{2}\right.$, AR $\left.99 \%\right)$, ammonia $\left(\mathrm{NH}_{3} * \mathrm{H}_{2} \mathrm{O}\right.$, AR 25-28\%), ethanol $\left(\mathrm{C}_{2} \mathrm{H}_{5} \mathrm{OH}\right.$, AR 99.7\%), commercial iridium carbon $(20 \mathrm{wt} \%)$ were purchased from Shanghai Aladdin Chemical Co., Ltd., monochloro acetic acid $\left(\mathrm{C}_{2} \mathrm{H}_{3} \mathrm{ClO}_{2}\right.$, AR 98\%) was purchased from Shanghai Macklin Biochemical Technology Co., Ltd., and acetone $\left(\mathrm{C}_{3} \mathrm{H}_{6} \mathrm{O}\right.$, AR 98\%), hydrochloric acid ( $\left.\mathrm{HCl}, 36.0-37.0 \%\right)$, nitric acid $\left(\mathrm{HNO}_{3}, 65.0-68.0 \%\right)$, sodium hydroxide $(\mathrm{NaOH}, \mathrm{AR} 96 \%)$, potassium hydroxide (KOH, AR 85\%) were produced by Guangzhou Chemical Reagent Factory. Nafion solution (D520, 5 wt\%) was supplied from DuPont. Carbon papers (TGP-H-060, $20 \mathrm{cmx} 20 \mathrm{~cm}, 0.19 \mathrm{~mm}$ ) were produced by Toray Corporation (Japan).

\subsection{Preparation of lignin-based CoFe supramolecules}

Carboxylated enzymatic hydrolyzed lignin (EHL-COOH) was prepared by the aqueous method according to our previous report ${ }^{51}$. Then $1.0 \mathrm{~g}$ EHL-COOH was dissolved in $100 \mathrm{~mL}$ pure water, while $\mathrm{FeCl}_{3} * 6 \mathrm{H}_{2} \mathrm{O}$ and $\mathrm{Co}\left(\mathrm{NO}_{3}\right)_{2} * 6 \mathrm{H}_{2} \mathrm{O}\left(\mathrm{n}_{\mathrm{Fe}} / \mathrm{n}_{\mathrm{Co}}=8: 0,7: 1,6: 2,4: 4,2: 6,1: 7,0: 8\right)$ were added into $50 \mathrm{~mL}$ pure water under vigorous stirring. The mixture was added drop by drop into the aqueous solution of EHL-COOH and stirred for $10 \mathrm{~min}$. The $\mathrm{pH}$ of above solution was adjusted to 8 by $\mathrm{NH}_{3}{ }^{*} \mathrm{H}_{2} \mathrm{O}$ and $\mathrm{HCl}$. After aging for $12 \mathrm{~h}$, the precipitate was centrifuged, washed with ultra-pure water, dried at 80 for $24 \mathrm{~h}$, and ground to obtain the lignin-based CoFe supramolecules (EHL-COOH-CoFe).

\subsection{Preparation of lignin-derived carbon $\mathrm{CoFe}-\mathrm{Co}_{\mathrm{x}} \mathrm{N} @ \mathrm{NC}$}

Firstly, $1.0 \mathrm{~g}$ of EHL-COOH-CoFe was ground and mixed with a certain amount of urea, then was heated at a rate of $5 * \mathrm{~min}^{-1}$ and pyrolyzed at high temperature for $2 \mathrm{~h}$ under the argon atmosphere. The products were washed with $1 \mathrm{~mol}^{*} \mathrm{~L}^{-1} \mathrm{HCl}$ and ultra-pure water, respectively, and dried at 80 for $12 \mathrm{~h}$ to obtain the bimetal-based functionalized nitrogen-doped lignin-derived carbon materials, denoted as $\mathrm{CoFe}-\mathrm{Co}_{\mathrm{x}} \mathrm{N} @ \mathrm{NC}$. The effects of metal ratio, pyrolysis temperature, the ratio of metal to lignin, and nitrogen content on the structure and electrocatalytic performance of $\mathrm{CoFe}-\mathrm{Co}_{\mathrm{x}} \mathrm{N} @ \mathrm{NC}$ were systematically investigated. $1.0 \mathrm{~g}$ of EHL-COOH was mixed and ground with $1.0 \mathrm{~g}$ of urea, then pyrolyzed at 700 to obtain the metal free nitrogen-doped lignin-derived carbon materials (NC) as comparative sample.

\subsection{Structural characterization of $\mathrm{CoFe}-\mathrm{Co}_{\mathrm{x}} \mathrm{N} @ \mathrm{NC}$}

The crystal structure of the electrocatalyst was characterized by Rigaku Miniflex-600 XRD instrument, which used a $\mathrm{Cu}-\mathrm{K} \alpha$ radiated X-ray source with a scanning range of $2 \theta=5-80$ and a scanning rate of $10^{\circ} \cdot \mathrm{min}^{-1}$. 
The morphology and elemental composition were characterized by American FEI Tecnai G ${ }^{2}$ F20 TEM, and its operating voltage was $200 \mathrm{kV}$. The degree of order and graphitization were characterized by LabRAM HR Evolution Raman spectrometer, with an excitation wavelength of $532 \mathrm{~nm}$. Nitrogen adsorption/desorption isotherms were measured at $77 \mathrm{~K}$ with ASAP 2460 surface area and porosity analyzer. The elemental composition and valence state were characterized by Thermo Scientific K-Alpha + X-ray photoelectron spectrometer (XPS). All the peaks were calibrated according to the standard position of C 1s peak (284.8 $\mathrm{eV}$ ). The percentage of doped metal in the sample was calculated by Varian 720 inductively coupled plasma OES spectrometer (ICP-OES). The band gap width of carbon materials was determined by PE Lambda 950 UV-Vis Diffuse Reflectance Spectrometer. The valence band and conduction band of carbon materials were tested by UV photoelectron spectrometer (Thermo Fischer Escalab $250 \mathrm{Xi}$ ).

\subsection{Electrochemical measurements}

All electrochemical measurements were performed in a three-electrode system using the Gamry Interface 1010 electrochemical workstation. Graphite rod and $\mathrm{Hg} / \mathrm{HgO}$ were used as the counter electrode and reference electrode, respectively. The working electrode was prepared as follows, $4 \mathrm{mg}$ of carbon powder was added into $200 \mu \mathrm{L}$ of $0.25 \%$ nafion-ethanol solution. After ultrasonic dispersion of the powder, $50 \mu \mathrm{L}$ of the slurry was dropped onto the treated carbon paper, and then the carbon paper was held by electrode clamp as the working electrode. The loading capacity of the catalyst was $4 \mathrm{mg} \cdot \mathrm{cm}^{-2}$.

The electrochemical performances were investigated by using linear sweep voltammetry (LSV) and cyclic voltammetry $(\mathrm{CV})$ techniques at room temperature. $1 \mathrm{~mol}^{*} \mathrm{~L}^{-1} \mathrm{KOH}$ solution was used as electrolyte, and the scanning rate recorded by all the polarization curves was $1 \mathrm{mV}^{*} \mathrm{~s}^{-1}$. Before LSV testing, the working electrode with loading catalyst was firstly activated by several CV cycles. All the measured data of the polarization curve were corrected by IR, and all the potentials were calculated according to the reversible hydrogen electrode (RHE). The expression is as follows:

$\mathrm{E}($ vs. $\mathrm{RHE})=\mathrm{E}($ vs. $\mathrm{Hg} / \mathrm{HgO})+0.098+0.0591 \times \mathrm{pH}$.

\subsection{Density functional theory (DFT) calculations}

DFT calculations were carried out using the Vienna ab Initio Simulation Package (VASP) ${ }^{52}$. The PerdewBurke-Ernzerhof (PBE) model in the form of the generalized gradient approximation (GGA) was used to describe the exchange-correlation potential. For all optimization calculations, the energy and force convergence criteria were set to $10^{-5} \mathrm{eV}$ and $0.05 \mathrm{ev}^{*} \mathrm{~A}^{-1}$, respectively. Total energy was calculated using the Projector Augmented-Wave (PAW) method with a plane-wave cutoff energy of $400 \mathrm{eV}$. A gamma-centered $\mathrm{K}$-point of $3 \times 3 \times 1$ was chosen to describe the Brillouin zone.

\section{Results and discussion}

\subsection{Synthesis and characterization of $\mathrm{CoFe}-\mathrm{Co}_{\mathrm{x}} \mathrm{N} @ \mathrm{NC}$}

The CoFe-Co $\mathrm{C}_{\mathrm{x}} \mathrm{N} @ \mathrm{NC}$ catalyst was synthesized by self-assembly and pyrolysis process, as shown in Fig. 1a. In brief, biorefinery lignin was carboxylated to improve its solubility and coordinated with $\mathrm{Co}^{2+}$ and $\mathrm{Fe}^{3+}$ to form the lignin-based CoFe supramolecules, followed by co-doping with urea and in situ pyrolyzing at high temperature to obtain the $\mathrm{CoFe}-\mathrm{Co}_{\mathrm{x}} \mathrm{N}$ heterojunction on the nitrogen-doped lignin-derived carbon.

The crystal phase structure and graphitization degree of $\mathrm{CoFe}-\mathrm{Co}_{\mathrm{x}} \mathrm{N} @ \mathrm{NC}$ samples were shown in Fig. 1 and Fig. S1. From the XRD patterns of the metal free nitrogen-doped lignin-derived carbon materials (NC) and CoFe-Co5.47 N@NC, it could be observed that the characteristic peaks of $\mathrm{NC}$ at the position of 24deg and $43 \mathrm{deg}$, respectively, which belonged to the (002) and (100) crystal planes of graphitic carbon ${ }^{53}$. When the 
Fe/Co ratio gradually decreased from 7:1 to 1:7, the XRD peaks of (110) and (200) planes of Fe (PDF\#060696) moved to a smaller angle and disappeared until the (111) and (200) planes of Co (PDF\#15-0806) appeared, and all the samples had a broad peak around 26deg attributed to the (002) plane of graphitic carbon, as shown in Fig. 1b. The dominant phase is bimetallic CoFe alloy with diffraction peaks centered at 44.9deg and 65.3deg, which can be ascribed to the (110) and (200) crystal planes of CoFe alloy (PDF\#491568). The diffraction peaks of $43.7 \mathrm{deg}, 50.8 \mathrm{deg}$ and $74.9 \mathrm{deg}$ corresponding to the (111), (200) and (220) crystal planes of $\mathrm{Co}_{5.47} \mathrm{~N}$ (PDF\#41-0943) were also observed ${ }^{54}$. The XRD peak of CoFe-Co ${ }_{5.47} \mathrm{~N} @ \mathrm{NC}$ moved towards a higher angle $(\sim 0.4 \mathrm{deg})$ relative to $\mathrm{Co}_{5.47} \mathrm{~N}$, which meant that the lattice expansion was due to the partial substitution of $\mathrm{Co}$ by $\mathrm{Fe}^{55}$. With the increase of pyrolysis temperature, the diffraction peak intensity belonging to the (002) crystal plane of graphitic carbon increased, the graphitization degree gradually increased as well as the electronic conductivity. With the increase of the urea dosages during the in situ pyrolysis process, the diffraction peak intensity of $43.7 \mathrm{deg}$ belong to the (111) plane of $\mathrm{Co}_{5.47} \mathrm{~N}$ increased continuously, indicating that the coordination between metal and nitrogen gradually increased, and nitrogen was successfully introduced into the lignin-derived carbon support. The optimal $\mathrm{Fe} / \mathrm{Co}$ ratio and urea dosage was beneficial to the formation of CoFe alloy and $\mathrm{Co}_{\mathrm{x}} \mathrm{N}$ heterojunction.

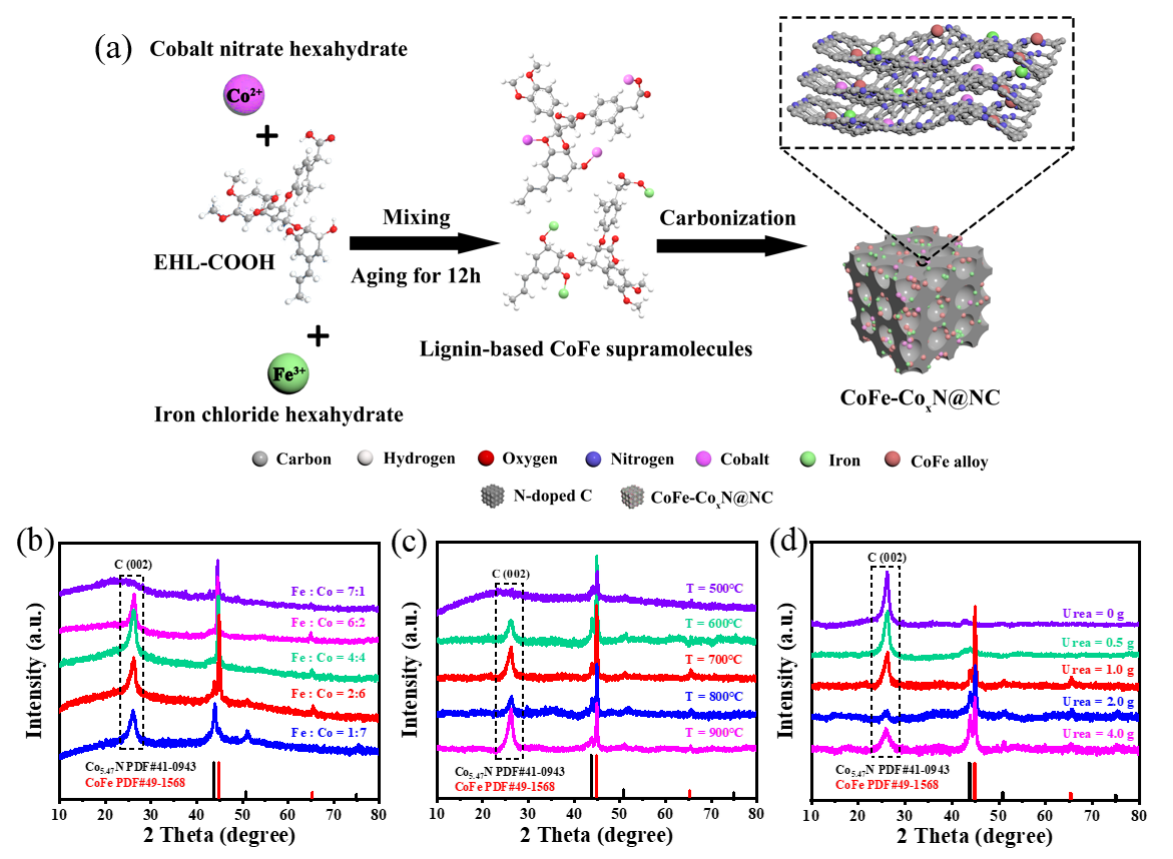

Fig. 1. (a) Synthesis route of $\mathrm{CoFe}-\mathrm{Co}_{\mathrm{x}} \mathrm{N} @ \mathrm{NC}$ heterojunction, XRD pattern of $\mathrm{CoFe}-\mathrm{Co}_{\mathrm{x}} \mathrm{N} @ \mathrm{NC}$ with various (b) metal ratios, (c) pyrolysis temperatures and (d) urea dosages

The delicate morphology of CoFe-Co $\mathrm{O}_{\mathrm{x}} \mathrm{N} @ \mathrm{NC}$ was investigated by SEM, TEM and HRTEM, as shown in Fig. 2. Compared with the metal free sample $\mathrm{NC}$, the pore structure of $\mathrm{CoFe}-\mathrm{Co}_{\mathrm{x}} \mathrm{N} @ \mathrm{NC}$ exposed more active sites and the metal particles were highly dispersed without agglomeration, thus would improve the catalytic activity. In addition, HRTEM images of $\mathrm{CoFe}-\mathrm{Co}_{\mathrm{x}} \mathrm{N} @ \mathrm{NC}$ in Fig. 3d-f showed the clear lattice of CoFe alloy nanoparticles and the lattice spacing was $0.202 \mathrm{~nm}$, which can be ascribed to the (110) diffraction plane of CoFe alloy; a distinct lattice fringe of $0.207 \mathrm{~nm}$, consistent with the (111) lattice plane of $\mathrm{Co}_{5.47} \mathrm{~N}$; the lattice spacing of the outer carbon layer is about $0.34 \mathrm{~nm}$, attributing to the $d$-spacing of the (002) plane in graphitic carbon. Moreover, the energy dispersive X-ray spectrometer (EDX) showed that Co, Fe, C, $\mathrm{N}$ and $\mathrm{O}$ elements were uniformly distributed along the surface of $\mathrm{CoFe}-\mathrm{Co}_{\mathrm{x}} \mathrm{N} @ \mathrm{NC}$ (Fig. 2g). $\mathrm{CoFe}-\mathrm{Co}_{\mathrm{x}} \mathrm{N}$ heterojunction particles with sizes ranging from $20.2 \mathrm{~nm}$ to $58.6 \mathrm{~nm}$ were encapsulated by the graphitic carbon layer and uniformly distributed on the carbon support. The SEM-EDX image of CoFe-Co5.47N@NC 
was shown in Fig. S5a, and the average particle size was $31.36 \mathrm{~nm}$ and the particle size distribution was shown in Fig. S5b. The results above proved the formation of $\mathrm{CoFe}$ alloy and $\mathrm{Co}_{\mathrm{x}} \mathrm{N}$ heterojunction encapsulated by the graphic carbon layers and located on the nitrogen-doped lignin-derived shell-core carbon support.
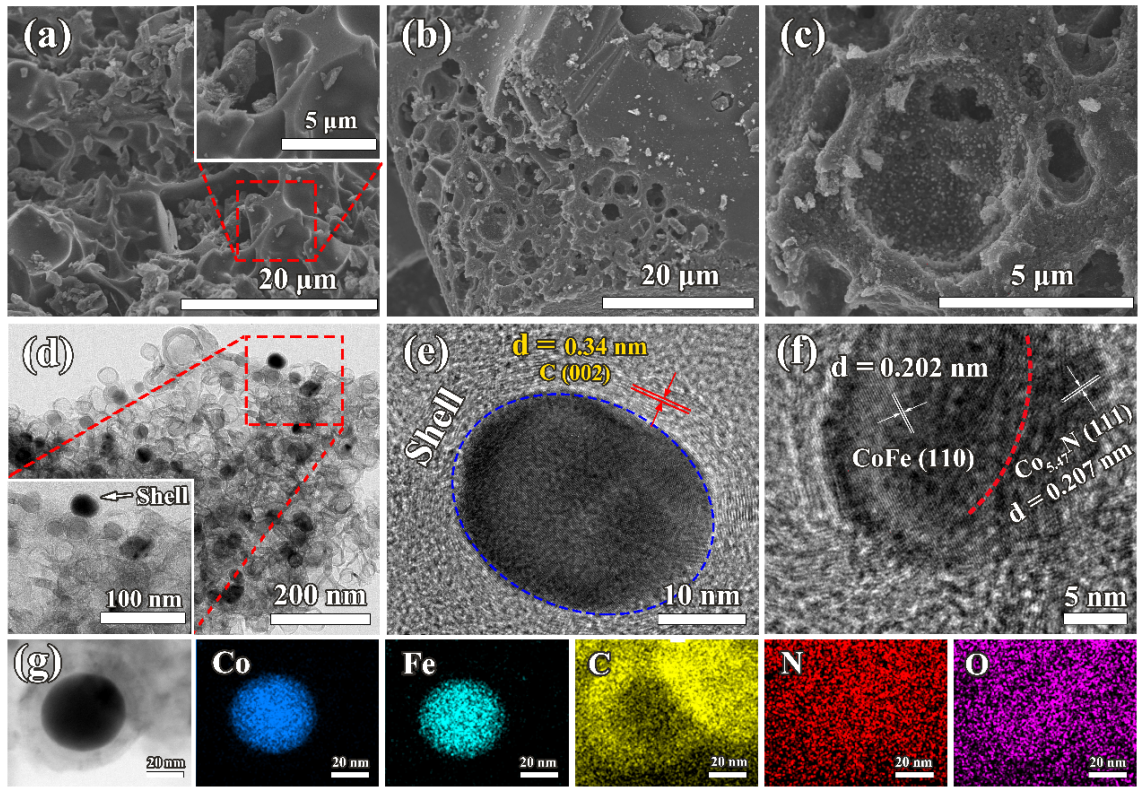

Fig. 2. SEM image of (a) NC and (b-c) CoFe-Co $\mathrm{Co}_{\mathrm{x}} \mathrm{N} @ \mathrm{NC}$, (d) TEM image, (e-f) HRTEM image and (g) elemental mappings of $\mathrm{Co}, \mathrm{Fe}, \mathrm{C}, \mathrm{N}$ and $\mathrm{O}$ of $\mathrm{CoFe}-\mathrm{Co}_{\mathrm{x}} \mathrm{N} @ \mathrm{NC}$

Raman spectroscopy was conducted to study the effect of pyrolysis temperatures on the composition of $\mathrm{CoFe}-\mathrm{Co}_{\mathrm{x}} \mathrm{N} @ \mathrm{NC}$, as shown in Fig. S6a. The D-band at $1340 \mathrm{~cm}^{-1}$ and the G-band at $1590 \mathrm{~cm}^{-1}$ represented the defect degree and graphitic degree of carbon, respectively. The degree of defects and graphitization could be measured by the intensity ratio of $\mathrm{I}_{\mathrm{D}} / \mathrm{I}_{\mathrm{G}}$. As the pyrolysis temperature increased from 500 to $800^{\circ} \mathrm{C}$, the $\mathrm{I}_{\mathrm{D}} / \mathrm{I}_{\mathrm{G}}$ increased from 0.92 to 1.12 ; when further increased the pyrolysis temperature, the $\mathrm{I}_{\mathrm{D}} / \mathrm{I}_{\mathrm{G}}$ decreased. The high degree of defect structure would lead to the increase of the adsorption capacity while the high degree of graphite structure would lead to the increase of electrical conductivity of the carbon material. The results suggested that $\mathrm{CoFe}-\mathrm{Co}_{\mathrm{x}} \mathrm{N} @ \mathrm{NC}$ pyrolysis at $700^{\circ} \mathrm{C}$ had the most suitable degree of defects and graphitization, thus had relative high adsorption capacity and high electrical conductivity, which was beneficial to promote the OER electrocatalytic performance. The porous character of $\mathrm{CoFe}-\mathrm{Co}_{\mathrm{x}} \mathrm{N} @ \mathrm{NC}$ was investigated by the $\mathrm{N}_{2}$ adsorption/desorption curve. There was an obvious hysteresis loop, which was a typical feature of the type IV isotherm adsorption curve, indicating that $\mathrm{CoFe}-\mathrm{Co}_{\mathrm{x}} \mathrm{N} @ \mathrm{NC}$ had the characteristics of hierarchical porous structure. Its specific surface area was $195.9 \mathrm{~m}^{2} \cdot \mathrm{g}^{-1}$ and the pore volume was $0.27 \mathrm{~cm}^{3 * \mathrm{~g}^{-1}}$. The macro- and mesoporous structure of the carbon material facilitated the adsorption transfer of $\mathrm{OH}^{-}$reactants and $\mathrm{O}_{2}$ products in OER, and the large specific surface area facilitated the contact of the active sites.

The chemical composition and valence state of $\mathrm{CoFe}-\mathrm{Co}_{\mathrm{x}} \mathrm{N} @ \mathrm{NC}$ were determined by XPS in Fig. 3 and Fig. S8. The XPS survey spectrum revealed the presence of $\mathrm{Co}, \mathrm{Fe}, \mathrm{O}, \mathrm{N}$ and $\mathrm{C}$ elements, which was consistent with the results of elemental mappings by TEM-EDX. The $\mathrm{C} 1 \mathrm{~s}$ spectrum confirmed the existence of C-C $(284.8 \mathrm{eV}), \mathrm{C}-\mathrm{N}(285.4 \mathrm{eV}), \mathrm{C}-\mathrm{O}(286.6 \mathrm{eV}), \mathrm{C}=\mathrm{O}(288.7 \mathrm{eV})$ and $\mathrm{O}-\mathrm{C}=\mathrm{O}(290.8 \mathrm{eV})$ in CoFe-Co $\mathrm{N}_{\mathrm{N}} @ \mathrm{NC}^{56}$ , $\mathrm{C}-\mathrm{N}$ bond indicated that nitrogen was successfully doped into the carbon skeleton, while the existence of $\mathrm{C}=\mathrm{O}$ and $\mathrm{O}-\mathrm{C}=\mathrm{O}$ implied substantial oxygen-containing groups decorated on the surface which can create defects in the carbon matrix. The N 1 s spectrum at the peaks of 398.6, 400.1, 401.1 and $403 \mathrm{eV}$ corresponded to pyridine $\mathrm{N}$ (38.53\%), pyrrole N (17.99\%), graphite $\mathrm{N}(33.45 \%)$ and pyridine N oxide (10.04\%), respectively 57,58 , the abundant pyridinic $\mathrm{N}$ can coordinate with metal atoms through metal- $\mathrm{N}-\mathrm{C}$ structure to optimize 
the local electronic structure, graphitic $\mathrm{N}$ was expected to improve the diffusion-limiting current, both benefiting the electrochemical process. In addition, the surface element content of $\mathrm{CoFe}-\mathrm{Co}_{\mathrm{x}} \mathrm{N} @ \mathrm{NC}$ with various urea dosages and the relative contents of the four nitrogen atoms were listed in Tab. S1 and S2, respectively. The hydrophilicity of carbon materials could be improved by the surface functional groups to balance the adsorption and desorption of intermediates and products during OER performance. As CoFe alloy in $\mathrm{CoFe}-\mathrm{Co}_{5.47} \mathrm{~N} @ \mathrm{NC}$ catalyst was encapsulated by the graphitic carbon layer, the spectral intensity of Fe 2p and Co 2p spectra in CoFe-Co $\mathrm{Co}_{\mathrm{x}} \mathrm{N} @ \mathrm{NC}$ catalyst was relatively weak, as shown in Fig. 3c-d. The Fe 2p spectrum of Fe@NC and the Co 2p spectrum of Co@NC was shown in Fig. S8. For the Fe 2p spectrum, the first double peak was 711.5 and $724.2 \mathrm{eV}$, and the second double peak was 713.9 and $727.3 \mathrm{eV}$, designated as $\mathrm{Fe}^{2+}$ and $\mathrm{Fe}^{3+}$, respectively ${ }^{59,60}$, and the peaks near $719.1 \mathrm{eV}$ and $735.2 \mathrm{eV}$ were classified as the satellite peaks of $\mathrm{Fe} 2 \mathrm{p}^{3 / 2}$ and $\mathrm{Fe} 2 \mathrm{p}^{1 / 2}$, respectively. Similarly, Co $2 \mathrm{p}$ spectrum showed the zero-valence state $(778.3$ and $795.2 \mathrm{eV}$ ) and the ionic state $(780.0$ and $797.4 \mathrm{eV})$ Co with satellite peaks (785.6 and 803.4eV), which are derived from $\mathrm{CoFe}$ alloy and $\mathrm{Co}_{\mathrm{x}} \mathrm{N}$ species, respectively.

\section{Hosted file}

image3.emf available at https://authorea.com/users/461489/articles/557177-in-situ-couplingof-n-doped-lignin-derived-carbon-encapsulated-cofe-coxn-heterojunction-for-oxygenevolution-reaction

Fig. 3. High-resolution XPS spectrum of CoFe-Co $\mathrm{N} @ \mathrm{NC}$ : (a) C 1s, (b) N 1s, (c) Fe 2p, (d) Co 2p

\subsection{Electrocatalytic performance of $\mathrm{CoFe}-\mathrm{Co}_{\mathrm{x}} \mathrm{N} @ \mathrm{NC}$}

The OER electrocatalytic activity of $\mathrm{CoFe}-\mathrm{Co}_{\mathrm{x}} \mathrm{N} @ \mathrm{NC}$ catalysts as investigated in a standard three-electrode system in 1.0 M KOH solution. The effects of the pyrolysis temperature, urea dosage, $\mathrm{Fe} / \mathrm{Co}$ metal ratio and metal/lignin ratio during synthesis process on the OER electrocatalytic activity of $\mathrm{CoFe}_{-} \mathrm{Co}_{\mathrm{x}} \mathrm{N} @ \mathrm{NC}$ were shown in Fig. 4 and Fig. S9-10. As the pyrolysis temperature increased, the overpotential required to achieve a current density of $10 \mathrm{~mA}^{*} \mathrm{~cm}^{-2}(\eta 10)$ using $\mathrm{CoFe}-\mathrm{Co}_{\mathrm{x}} \mathrm{N} @ \mathrm{NC}$ catalyst decreased at first and then increased at the temperature of 700, which was related to the degree of defects and graphitization of the carbon material. The low pyrolysis temperature leaded to incomplete carbonization of the sample, thus showed poor electrical conductivity that seriously affected the OER electrocatalytic activity. Excessive pyrolysis temperature leaded to the metal agglomeration and pore blockage, thus reduced the OER electrocatalytic activity. When the optimal ratio of urea and EHL-COOH-CoFe precursor was 1:1, CoFe- $\mathrm{Co}_{\mathrm{x}} \mathrm{N} @ \mathrm{NC}$ exhibited the lowest overpotential $\eta 10$ of $270 \mathrm{mV}$, that was much lower than that of $\mathrm{CoFe} @ \mathrm{C}$ catalyst without the doping of urea $(340 \mathrm{mV})$. The active sites of pyridine $\mathrm{N}$ and graphite $\mathrm{N}$ could promote the synergistic interaction between nitrogen and $\mathrm{CoFe}$ alloy, the $\mathrm{Co}_{\mathrm{x}} \mathrm{N}$ composition in $\mathrm{CoFe}-\mathrm{Co}_{\mathrm{x}} \mathrm{N} @ \mathrm{NC}$ would increase from the XRD patterns (Fig. 1d) with the increasing dosage of urea during the in situ pyrolysis process, therefore, the composition ratio of $\mathrm{CoFe}$ alloy and $\mathrm{Co}_{\mathrm{x}} \mathrm{N}$ heterojunction decreased that caused the inferior OER electrocatalytic activity of $\mathrm{CoFe}-\mathrm{Co}_{\mathrm{x}} \mathrm{N} @ \mathrm{NC}$.

Monolithic Co-based catalyst was insufficient to deliver the ideal OER electrocatalytic activity and stability. Rational synthesis of bimetallic CoFe alloy was investigated through the partial substitution with $\mathrm{Fe}$, and the metal composition content in $\mathrm{CoFe}-\mathrm{Co}_{\mathrm{x}} \mathrm{N} @ \mathrm{NC}$ determined by ICP-OES was shown in Table S3. With the increase of substitution with $\mathrm{Fe}$ based on the atomic ratio of $\mathrm{Fe}$ and $\mathrm{Co}$ to $21 \%$, the overpotential $\eta 10$ was decreased to $270 \mathrm{mV}$, while that of $\mathrm{Co} @ \mathrm{NC}$ was $340 \mathrm{mV}$; further increased the Fe composition content, Fe became the major active composition, $\mathrm{Co}_{\mathrm{x}} \mathrm{N}$ content in $\mathrm{CoFe}-\mathrm{Co}_{\mathrm{x}} \mathrm{N} @ \mathrm{NC}$ decreased and ever disappeared verified by the XRD patterns in Fig. 1b, thus decreased the overpotential $\eta 10$ to $416 \mathrm{mv}$ with the Fe substitution of $96 \%$, while that of $\mathrm{Fe} @ \mathrm{NC}$ was $448 \mathrm{mV}$. With the increase of the ratio of metal moles and lignin to $8 \mathrm{mM} / \mathrm{g}$ in the self-assembly coordination with $\mathrm{Fe}^{3+}$ and $\mathrm{Co}^{2+}$ process, CoFe- $\mathrm{Co}_{\mathrm{x}} \mathrm{N} @ \mathrm{NC}$ showed the optimal OER performance. Based the results above, the optimal synthesis parameters were the pyrolysis temperature of 700, the ratio of metal moles and lignin of $8 \mathrm{mM} / \mathrm{g}$, the atomic ratio of Fe:Co $=2: 6$, the ratio of urea and EHL-COOH-CoFe precursor of 1:1, and the metal content of the corresponding $\mathrm{CoFe}-\mathrm{Co}_{\mathrm{x}} \mathrm{N} @ \mathrm{NC}$ 
was $1.45 \mathrm{wt} \%$ of $\mathrm{Fe}$ and $5.60 \mathrm{wt} \%$ of Co. The overpotential $\eta 10$ of $\mathrm{CoFe}-\mathrm{Co}_{\mathrm{x}} \mathrm{N} @ \mathrm{NC}$ material was $270 \mathrm{mV}$ with a Tafel slope of $85 \mathrm{mV} \cdot \mathrm{dec}^{-1}$, which could be comparable to the performance of commercial Ir/C catalyst $\left(252 \mathrm{mV} @ 10 \mathrm{~mA}^{*} \mathrm{~cm}^{-2}, 82 \mathrm{mV}^{*} \mathrm{dec}^{-1}\right)$.

\section{Hosted file}

image4.emf available at https://authorea.com/users/461489/articles/557177-in-situ-couplingof-n-doped-lignin-derived-carbon-encapsulated-cofe-coxn-heterojunction-for-oxygen-

evolution-reaction

Fig. 4. Effect of (a-b) pyrolysis temperature, (c-d) urea dosage and (e-f) Fe/Co ratio on the OER electrocatalytic activity of $\mathrm{CoFe}-\mathrm{Co}_{\mathrm{x}} \mathrm{N} @ \mathrm{NC}$ by LSV measurement and its corresponding Tafel slop

The stability of electrocatalyst was another key feature in practical applications. The stability of CoFe$\mathrm{Co}_{\mathrm{x}} \mathrm{N} @ \mathrm{NC}$ for OER was evaluated by the chronopotentiometri measurement recorded at a constant current density of $10 \mathrm{~mA}^{*} \mathrm{~cm}^{-2}$, as show in Fig. 5. After the continuous test for $80000 \mathrm{~s}$, the overpotential of CoFe$\mathrm{Co}_{\mathrm{x}} \mathrm{N} @ \mathrm{NC}$ kept well-maintained, of which just increased by about $20 \mathrm{mV}$. The TEM images, TEM-mapping

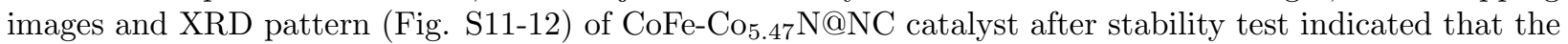
structure and morphology of the catalyst remains unchanged. From the electrocatalytic performance above, the catalytic activity and stability of $\mathrm{CoFe}-\mathrm{Co}_{\mathrm{x}} \mathrm{N} @ \mathrm{NC}$ for OER was mainly attributed to the active sites of $\mathrm{CoFe}-\mathrm{Co}_{5.47} \mathrm{~N}$ heterogeneous structure encapsulated by the graphic carbon layers and embedded in the nitrogen-doped lignin-derived shell-core carbon material.

\section{Hosted file}

image5.emf available at https://authorea.com/users/461489/articles/557177-in-situ-couplingof-n-doped-lignin-derived-carbon-encapsulated-cofe-coxn-heterojunction-for-oxygenevolution-reaction

Fig.5. (a) the LSV curve of $\mathrm{CoFe}-\mathrm{Co}_{\mathrm{x}} \mathrm{N} @ \mathrm{NC}$ for OER before and after the 80000 s cycle at a constant current density of $10 \mathrm{~mA}^{*} \mathrm{~cm}^{-2}$, (b) the chronopotentiometri measurement of recorded at a constant current density of $10 \mathrm{~mA}^{*} \mathrm{~cm}^{-2}$ for $\mathrm{CoFe}-\mathrm{Co}_{\mathrm{x}} \mathrm{N} @ \mathrm{NC}$

\subsection{Electrocatalytic mechanism}

In order to provide insights into the electrocatalytic mechanism of $\mathrm{CoFe}-\mathrm{Co}_{\mathrm{x}} \mathrm{N} @ \mathrm{NC}$ for OER, DFT calculation was employed to investigate and compare the OER catalytic performances of four catalyst models including naked FeCo alloy, FeCo alloy encapsulated by carbon layer (CoFe@C), CoFe alloy encapsulated by nitrogendoped carbon layer (CoFe@NC), and the as-prepared $\mathrm{CoFe}-\mathrm{Co}_{\mathrm{x}} \mathrm{N} @ \mathrm{NC}$. Generally, OER undergoes a fourelectron step pathway in a basic electrolyte showed as Fig. 6a. The Gibbs free energy profiles for four catalysts were depicted in Fig. 6b, and the rate-determining step (RDS) with the value of the Gibbs free energy barrier was highlighted, where a fairly high Gibbs free energy barrier of $1.71 \mathrm{eV}$ was obtained at 1.23 $\mathrm{V}$ for OER over naked CoFe alloy. The reason for this mainly attributed to the strong absorption (a Gibbs free energy barrier of $-1.93 \mathrm{eV}$ ) of the active oxygen on the surface of $\mathrm{CoFe}$ alloy to form an excessively stable ${ }^{*} \mathrm{O}$ intermediate for OER. The charge density differences presented in Fig. S13 showed that charges were almost transferred onto the surface of oxygen atom, further revealing the enhanced electrostatic interaction between oxygen and $\mathrm{CoFe}$ alloy. In such case, more energies were required to overcome the barrier from * $\mathrm{O}$ to *OOH, resulting in the high overpotential for OER over CoFe alloy. Theoretically, CoFe alloy encapsulated by graphitic carbon layer can prevent it from the direct contact with reactive oxygen species, however, the interfacial distance between $\mathrm{CoFe}$ alloy and graphitic carbon layer would affect the stability and charge transfer. It can be seen from Fig. 6c that the total energy of the CoFe@C heterojunction catalyst was lowest when the interfacial distance reached $4 \mathrm{~A}$. Nevertheless, the electrons mainly accumulated in its interfacial space at its most stable configuration based on the charge density difference showed in Fig. 6c inserted images, making the active site to ${ }^{*} \mathrm{OH}$ pathway as the RDS with the high energy barrier of $1.56 \mathrm{eV}$. Interestingly, doping nitrogen in the graphitic carbon layer can redistribute the charge density without sacrificing its 
stability. The electrons transferred from CoFe alloy can be well distributed on the nitrogen-doped graphitic carbon layer as described in Fig. 6d-e, promoting the OER process with a lower energy barrier of $0.68 \mathrm{eV}$ at $\mathrm{RDS}$ from ${ }^{*} \mathrm{O}$ to ${ }^{*} \mathrm{OOH}$. Actually, in this study, in situ nitrogen-doping pyrolysis process can form a specific heterojunction $\mathrm{CoFe}-\mathrm{Co}_{\mathrm{x}} \mathrm{N} @ \mathrm{NC}$ with three phases, nitrogen-doped $\mathrm{Co}_{5.47} \mathrm{~N}$-connected CoFe alloy. The $\mathrm{Co}_{\mathrm{x}} \mathrm{N}$ as a linker can induce the uniform distribution of charge density as shown in Fig. $6 \mathrm{f}$ based on the DFT simulation, which could optimize the adsorption/desorption strength of the OER intermediates and products. As a result, a lowest limiting energy barrier of $0.43 \mathrm{eV}$ can be achieved by DFT calculation at $1.23 \mathrm{~V}$ for OER over CoFe-Co $\mathrm{o}_{\mathrm{x}} \mathrm{N} @ \mathrm{NC}$ (Fig. 6b) in comparison with other used catalysts, in consistent with the trend of experimental results.
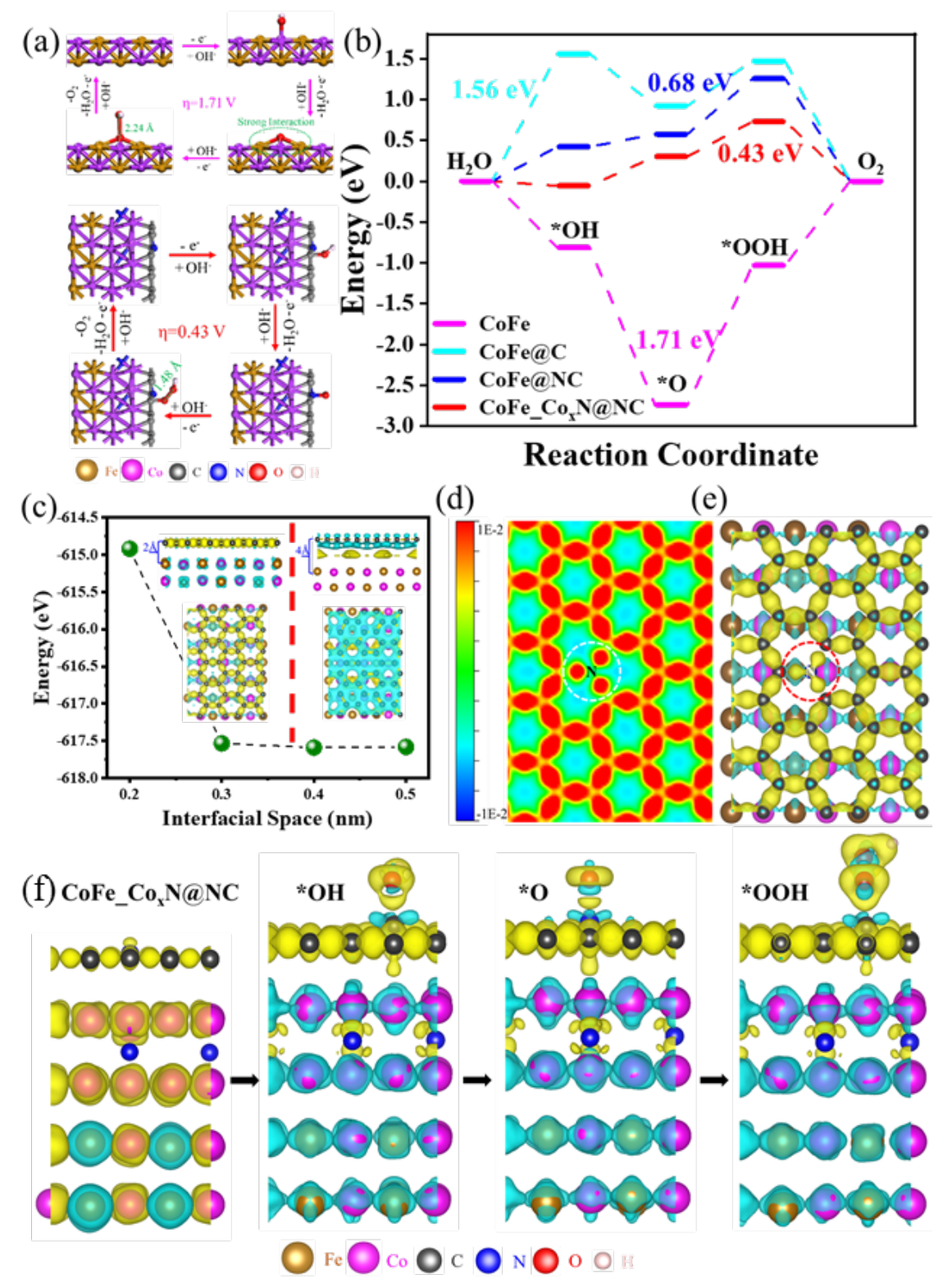

Fig. 6. Catalytic activity evaluated by DFT simulation. (a) Proposed reaction circle with geometryoptimized intermediates for OER over CoFe alloy and $\mathrm{CoFe}-\mathrm{Co}_{\mathrm{x}} \mathrm{N} @ \mathrm{NC}$, respectively. (b) Gibbs free energy profiles at $1.23 \mathrm{~V}$ for OER over $\mathrm{CoFe}$ alloy, $\mathrm{CoFe} @ \mathrm{C}$, CoFe@NC and $\mathrm{CoFe}-\mathrm{Co}_{\mathrm{x}} \mathrm{N} @ \mathrm{NC}$, respectively. (c) 
Effect of interfacial space between CoFe alloy and carbon layers on the stability of heterojunction catalysts, where yellow and cyan regions indicate increased and decreased charge distributions, respectively in the inserted images. (d) 2D and (e) 3D display of charge density difference of $\mathrm{CoFe} @ \mathrm{C}$ doped with $\mathrm{N}$ element $(\mathrm{CoFe} @ \mathrm{NC})$. (f) Charge density difference of intermediates for OER over $\mathrm{CoFe}-\mathrm{Co}_{\mathrm{x}} \mathrm{N} @ \mathrm{NC}$

\section{Conclusions}

In situ coupling strategy of $\mathrm{CoFe}$ alloy and $\mathrm{Co}_{\mathrm{x}} \mathrm{N}$ heterojunction encapsulated and embedded in the nitrogendoped lignin-derived carbon $\mathrm{CoFe}-\mathrm{Co}_{\mathrm{x}} \mathrm{N} @ \mathrm{NC}$ was provided to create a novelty highly active and stable electrocatalyst for oxygen evolution reaction. Biorefinery lignin was first carboxylated to improve its solubility and precisely coordinated with metal ions to form the coordination polymer precursor, that promoted the dispersion of metal active component and the encapsulated grapheme lawyer of $\mathrm{CoFe}$ alloy and $\mathrm{Co}_{\mathrm{x}} \mathrm{N}$ heterojunction. $\mathrm{CoFe}-\mathrm{Co}_{\mathrm{x}} \mathrm{N} @ \mathrm{NC}$ exhibited an excellent OER activity with the lowest overpotential of $270 \mathrm{mV}$ at $10 \mathrm{~mA} \cdot \mathrm{cm}^{-2}$ and stability with the only increment of $20 \mathrm{mV}$ after $80000 \mathrm{~s}$ in the alkaline media, comparable to that of commercial Ir/C catalyst. The as-prepared catalyst with high activity and cycle stability was attributed to the synergistic effect of $\mathrm{CoFe}$ alloy, $\mathrm{Co}_{\mathrm{x}} \mathrm{N}$ and nitrogen-doped encapsulated grapheme lawyer, that reduce the adsorption strength between ${ }^{*} \mathrm{O}$ and $\mathrm{CoFe}$ alloy, prevent metals leaching and agglomeration, and improve the electron transfer efficiency. This method not only turned waste into treasure from biomass waste lignin, but also provided a solution for the replacement of precious metal catalysts in the field of renewable energy conversion and storage.

\section{Acknowledgements}

The authors acknowledge the financial support of the National Natural Science Foundation of China (22038004, 22078069 and 22178069), the Guangdong Basic and Applied Basic Research Foundation (2019B151502038 and 2021A1515012354), Guangdong Provincial Key Research and Development Program (2020B1111380002), and the Guangdong Provincial Key Laboratory of Plant Resources Biorefinery (2021GDKLPRB-K05).

\section{References}

1. Yu ZY, Duan Y, Feng XY, Yu X, Gao MR, Yu SH. Clean and Affordable Hydrogen Fuel from Alkaline Water Splitting: Past, Recent Progress, and Future Prospects. Adv. Mater. 2021;33(31):e2007100.

2. Luo Y, Zhang Z, Chhowalla M, Liu B. Recent Advances in Design of Electrocatalysts for High-CurrentDensity Water Splitting.Adv. Mater. 2021:e2108133.

3. Jiao Y, Zheng Y, Jaroniec M, Qiao SZ. Design of electrocatalysts for oxygen- and hydrogen-involving energy conversion reactions. Chem. Soc. Rev. 2015;44(8):2060-2086.

4. Suen NT, Hung SF, Quan Q, Zhang N, Xu YJ, Chen HM. Electrocatalysis for the oxygen evolution reaction: recent development and future perspectives. Chem. Soc. Rev. 2017;46(2):337-365.

5. Antolini E. Iridium As Catalyst and Cocatalyst for Oxygen Evolution/Reduction in Acidic Polymer Electrolyte Membrane Electrolyzers and Fuel Cells. ACS Catalysis. 2014;4(5):1426-1440.

6. McCrory CC, Jung S, Peters JC, Jaramillo TF. Benchmarking heterogeneous electrocatalysts for the oxygen evolution reaction.J. Am. Chem. Soc. 2013;135(45):16977-16987.

7. Lee Y, Suntivich J, May KJ, Perry EE, Shao-Horn Y. Synthesis and Activities of Rutile IrO2 and RuO2 Nanoparticles for Oxygen Evolution in Acid and Alkaline Solutions. J Phys Chem Lett.2012;3(3):399-404. 
8. Lyu F, Wang Q, Choi SM, Yin Y. Noble-Metal-Free Electrocatalysts for Oxygen Evolution. Small.2019;15(1):e1804201.

9. Wang J, Cui W, Liu Q, Xing Z, Asiri AM, Sun X. Recent Progress in Cobalt-Based Heterogeneous Catalysts for Electrochemical Water Splitting. Adv. Mater. 2016;28(2):215-230.

10. Gong M, Dai HJ. A mini review of NiFe-based materials as highly active oxygen evolution reaction electrocatalysts. Nano Research. 2015;8(1):23-39.

11. Osgood H, Devaguptapu SV, Xu H, Cho J, Wu G. Transition metal (Fe, Co, Ni, and Mn) oxides for oxygen reduction and evolution bifunctional catalysts in alkaline media. Nano Today.2016;11(5):601-625.

12. Li T, Lv Y, Su J, et al. Anchoring CoFe2O4 Nanoparticles on N-Doped Carbon Nanofibers for HighPerformance Oxygen Evolution Reaction. Adv. Sci. 2017;4(11):1700226.

13. Tan L, Pan Q-R, Wu X-T, Li N, Song J-H, Liu Z-Q. Core@Shelled Co/CoO Embedded Nitrogen-Doped Carbon Nanosheets Coupled Graphene as Efficient Cathode Catalysts for Enhanced Oxygen Reduction Reaction in Microbial Fuel Cells. ACS Sustainable Chemistry 83 Engineering. 2019;7(6):6335-6344.

14. Wang Y, Zhang Y, Liu Z, et al. Layered Double Hydroxide Nanosheets with Multiple Vacancies Obtained by Dry Exfoliation as Highly Efficient Oxygen Evolution Electrocatalysts. Angew. Chem. Int. Ed. 2017;56(21):5867-5871.

15. Gao Z-W, Ma T, Chen X-M, et al. Strongly Coupled CoO Nanoclusters/CoFe LDHs Hybrid as a Synergistic Catalyst for Electrochemical Water Oxidation. Small. 2018;14(17):1800195.

16. Song L, Zhang J, Sarkar S, et al. Interface engineering of FeCo-Co structure as bifunctional oxygen electrocatalyst for rechargeable zinc-air batteries via alloying degree control strategy.Chem. Eng. J. 2022;433:133686.

17. Liu M, Li N, Cao S, et al. A "Pre-Constrained Metal Twins" Strategy to Prepare Efficient Dual-MetalAtom Catalysts for Cooperative Oxygen Electrocatalysis. Adv. Mater. 2021:e2107421.

18. Bai L, Hsu CS, Alexander DTL, Chen HM, Hu X. A Cobalt-Iron Double-Atom Catalyst for the Oxygen Evolution Reaction. J. Am. Chem. Soc. 2019;141(36):14190-14199.

19. Guan BY, Lu Y, Wang Y, Wu MH, Lou XW. Porous Iron-Cobalt Alloy/Nitrogen-Doped Carbon Cages Synthesized via Pyrolysis of Complex Metal-Organic Framework Hybrids for Oxygen Reduction. Adv. Funct. Mater. 2018;28(10):1706738.

20. Wang S, Wang H, Huang C, et al. Trifunctional electrocatalyst of N-doped graphitic carbon nanosheets encapsulated with CoFe alloy nanocrystals: The key roles of bimetal components and high-content graphiticN. Applied Catalysis B: Environmental.2021;298:120512.

21. Jin $\mathrm{T}$, Liu X, Gao Q, et al. Pyrolysis-free, facile mechanochemical strategy toward cobalt singleatom/nitrogen-doped carbon for highly efficient water splitting. Chem. Eng. J.2022;433:134089.

22. Wang Z, Xiao S, Zhu Z, et al. Cobalt-Embedded Nitrogen Doped Carbon Nanotubes: A Bifunctional Catalyst for Oxygen Electrode Reactions in a Wide pH Range. ACS Appl. Mater. Interfaces.2015;7(7):40484055 .

23. Du Y, Chen J, Li L, Shi H, Shao K, Zhu M. Core-Shell FeCo Prussian Blue Analogue/Ni(OH)2 Derived Porous Ternary Transition Metal Phosphides Connected by Graphene for Effectively Electrocatalytic Water Splitting. ACS Sustainable Chemistry \& Engineering.2019;7(15):13523-13531.

24. Yu M, Budiyanto E, Tuysuz H. Principles of Water Electrolysis and Recent Progress in Cobalt-, Nickel-, and Iron-Based Oxides for the Oxygen Evolution Reaction. Angew. Chem. Int. Ed.2022;61(1):e202103824. 
25. Su CY, Cheng H, Li W, et al. Atomic Modulation of FeCo-Nitrogen-Carbon Bifunctional Oxygen Electrodes for Rechargeable and Flexible All-Solid-State Zinc-Air Battery. Advanced Energy Materials. 2017;7(13):1602420.

26. Bai LC, Hsu CS, Alexander DTL, Chen HM, Hu XL. Double-atom catalysts as a molecular platform for heterogeneous oxygen evolution electrocatalysis. Nature Energy. 2021;6(11):1054-1066.

27. Wang YJ, Fan HB, Ignaszak A, et al. Compositing doped-carbon with metals, non-metals, metal oxides, metal nitrides and other materials to form bifunctional electrocatalysts to enhance metal-air battery oxygen reduction and evolution reactions. Chem. Eng. J. 2018;348:416-437.

28. Wang J, Kong H, Zhang JY, Hao Y, Shao ZP, Ciucci F. Carbon-based electrocatalysts for sustainable energy applications.Prog. Mater Sci. 2021;116:100717.

29. Li CL, Wu MC, Liu R. High-performance bifunctional oxygen electrocatalysts for zinc-air batteries over mesoporous $\mathrm{Fe} / \mathrm{Co}-\mathrm{N}-\mathrm{C}$ nanofibers with embedding FeCo alloy nanoparticles. Applied Catalysis BEnvironmental. 2019;244:150-158.

30. Zhu X, Jin T, Tian C, et al. In Situ Coupling Strategy for the Preparation of FeCo Alloys and Co4 N Hybrid for Highly Efficient Oxygen Evolution. Adv. Mater. 2017;29(47):1704091.

31. Meng F, Zhong H, Bao D, Yan J, Zhang X. In Situ Coupling of Strung Co4N and Intertwined N-C Fibers toward Free-Standing Bifunctional Cathode for Robust, Efficient, and Flexible Zn-Air Batteries. $J$. Am. Chem. Soc. 2016;138(32):10226-10231.

32. Shi QR, Zhu CZ, Du D, Lin YH. Robust noble metal-based electrocatalysts for oxygen evolution reaction. Chem. Soc. Rev.2019;48(12):3181-3192.

33. Zhang LL, Xiao J, Wang HY, Shao MH. Carbon-Based Electrocatalysts for Hydrogen and Oxygen Evolution Reactions. ACS Catalysis. 2017;7(11):7855-7865.

34. Cui XJ, Ren PJ, Deng DH, Deng J, Bao XH. Single layer graphene encapsulating non-precious metals as high-performance electrocatalysts for water oxidation. Energy \& Environmental Science. 2016;9(1):123-129.

35. Deng J, Ren P, Deng D, Bao X. Enhanced electron penetration through an ultrathin graphene layer for highly efficient catalysis of the hydrogen evolution reaction. Angew. Chem. Int. Ed.2015;54(7):2100-2104.

36. Deng J, Deng D, Bao X. Robust Catalysis on 2D Materials Encapsulating Metals: Concept, Application, and Perspective. Adv. Mater. 2017;29(43):1606967.

37. Su J, Yang Y, Xia G, Chen J, Jiang P, Chen Q. Ruthenium-cobalt nanoalloys encapsulated in nitrogen-doped graphene as active electrocatalysts for producing hydrogen in alkaline media.Nat. Commun. 2017;8(1):14969.

38. Ragauskas AJ, Beckham GT, Biddy MJ, et al. Lignin valorization: Improving lignin processing in the biorefinery.Science. 2014;344(6185):12013-12018.

39. Wright A, Bandulasena $\mathrm{H}$, Ibenegbu $\mathrm{C}$, et al. Dielectric barrier discharge plasma microbubble reactor for pretreatment of lignocellulosic biomass. AIChE Journal. 2018;64(11):3803-3816.

40. Wang J, Qian Y, Zhou Y, Yang D, Qiu X. Atomic Force Microscopy Measurement in the Lignosulfonate/Inorganic Silica System: From Dispersion Mechanism Study to Product Design. Engineering.2021;7(8):1140-1148.

41. Qi Y, Xiao X, Mei YQ, et al. Modulation of Bronsted and Lewis Acid Centers for NixCo3-xO4 Spinel Catalysts: Towards Efficient Catalytic Conversion of Lignin. Adv. Funct. Mater.2022;n/a(n/a):2111615.

42. Shen YX, Peng F, Cao YH, Zuo JH, Wang HJ, Yu H. Preparation of nitrogen and sulfur co-doped ultrathin graphitic carbon via annealing bagasse lignin as potential electrocatalyst towards oxygen reduction reaction in alkaline and acid media. Journal of Energy Chemistry.2019;34:33-42. 
43. Wu Y, Cao JP, Zhao XY, et al. High-performance electrode material for electric double-layer capacitor based on hydrothermal pre-treatment of lignin by $\mathrm{ZnCl}_{2}$. Appl Surf Sci.2020;508:144536-144547.

44. Gomez-Aviles A, Penas-Garzon M, Bedia J, Rodriguez JJ, Belver C. C-modified $\mathrm{TiO}_{2}$ using lignin as carbon precursor for the solar photocatalytic degradation of acetaminophen. Chemical Engineering Journal. 2019;358:1574-1582.

45. Zhang B, Yang D, Qiu X, et al. Fabricating $\mathrm{ZnO} /$ lignin-derived flower-like carbon composite with excellent photocatalytic activity and recyclability. Carbon.2020;162:256-266.

46. Qin HF, Zhou Y, Bai JR, et al. Lignin-Derived Thin-Walled Graphitic Carbon-Encapsulated Iron Nanoparticles: Growth, Characterization, and Applications. ACS Sustainable Chemistry \&5 Engineering. 2017;5(2):1917-1923.

47. Qin HF, Kang SF, Wang YG, et al. Lignin-Based Fabrication of Co@C Core-Shell Nanoparticles as Efficient Catalyst for Selective Fischer-Tropsch Synthesis of C5+ Compounds. Acs Sustainable Chemistry E3 Engineering. 2016;4(3):1240-1247.

48. Fei X, Xu Q, Xue L, et al. Aqueous Phase Catalytic Conversion of Ethanol to Higher Alcohols over NiSn Bimetallic Catalysts Encapsulated in Nitrogen-Doped Biorefinery Lignin-Based Carbon.Ind. Eng. Chem. Res. 2021;60(49):17959-17969.

49. Pei YX, Chang AY, Liu X, et al. Nitrogen-doped carbon dots from Kraft lignin waste with inorganic acid catalyst and their brain cell imaging applications. Aiche Journal. 2021;67(5):e17132.

50. Chen X, Yuan B, Yu F, Xie C, Yu S. Lignin: A Potential Source of Biomass-Based Catalysts. Progress in Chemistry.2021;33(2):303-317.

51. Linhuo G, Mingsong Z, Dongjie Y, Xueqing Q. Preparation and Evaluation of Carboxymethylated Lignin as Dispersant for Aqueous Graphite Suspension Using Turbiscan Lab Analyzer. Journal of Dispersion Science and Technology. 2013;34(5):644-650.

52. Blochl PE, Jepsen O, Andersen OK. Improved tetrahedron method for Brillouinzone integrations. Physical Review B.1994;49(23):16223-16233.

53. Pang J, Zhang W, Zhang H, et al. Sustainable nitrogen-containing hierarchical porous carbon spheres derived from sodium lignosulfonate for high-performance supercapacitors. Carbon. 2018;132:280-293.

54. Rong Z, Dong C, Zhang S, Dong W, Huang F. Co5.47N loaded N-doped carbon as an efficient bifunctional oxygen electrocatalyst for a Zn-air battery. Nanoscale. 2020;12(10):6089-6095.

55. Jin $\mathrm{H}$, Mao S, Zhan G, Xu F, Bao X, Wang Y. Fe incorporated $\alpha-\mathrm{Co}(\mathrm{OH}) 2$ nanosheets with remarkably improved activity towards the oxygen evolution reaction. Journal of Materials Chemistry A.2017;5(3):10781084 .

56. Liu Y, Li J, Li F, et al. A facile preparation of $\mathrm{CoFe} 2 \mathrm{O} 4$ nanoparticles on polyaniline-functionalised carbon nanotubes as enhanced catalysts for the oxygen evolution reaction. Journal of Materials Chemistry A. 2016;4(12):4472-4478.

57. Pang J, Zhang W, Zhang J, Cao G, Han M, Yang Y. Facile and sustainable synthesis of sodium lignosulfonate derived hierarchical porous carbons for supercapacitors with high volumetric energy densities. Green Chemistry. 2017;19(16):3916-3926.

58. Zhou H, Xu H, Liu Y. Aerobic oxidation of 5-hydroxymethylfurfural to 2,5-furandicarboxylic acid over Co/Mn-lignin coordination complexes-derived catalysts. Applied Catalysis B: Environmental. 2019;244:965973.

59. Wu MJ, Wei QL, Zhang GX, et al. Fe/Co Double Hydroxide/Oxide Nanoparticles on N-Doped CNTs as Highly Efficient Electrocatalyst for Rechargeable Liquid and Quasi-Solid-State Zinc-Air Batteries. Advanced 
Energy Materials. 2018;8(30):1801836.

60. Liu $\mathrm{H}, \mathrm{Lu} \mathrm{X}, \mathrm{Hu} \mathrm{Y}$, et al. CoxFeyN nanoparticles decorated on graphene sheets as high-performance electrocatalysts for the oxygen evolution reaction. Journal of Materials Chemistry A.2019;7(20):12489-12497.

\section{Graphical Abstract}

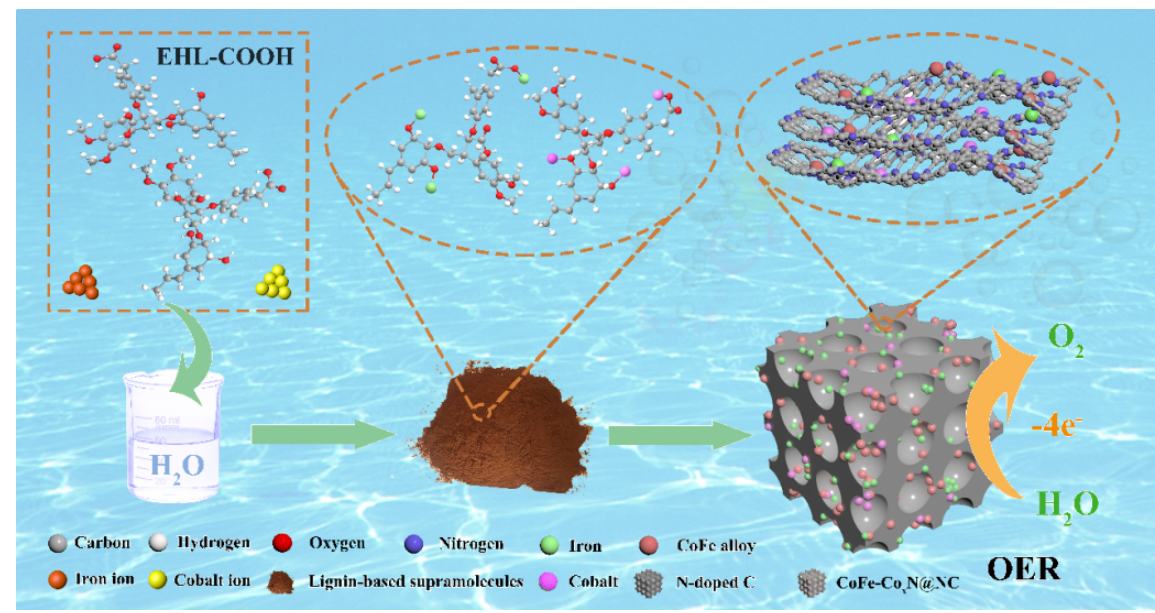

